\title{
A Case Report of Recurrent Fibrosis in Case of Transverse Vaginal Septum
}

\author{
${ }^{1}$ Disha Paryani, ${ }^{2}$ Ajesh Desai, ${ }^{3}$ Kunur Shah, ${ }^{4}$ Swati Nilay Patel
}

\begin{abstract}
Transverse vaginal septum is a rare mullerian duct anomaly due to vertical fusion defect. A 21-year-old female presented with secondary amenorrhea and lower abdominal pain for 6 years. She had past history of hematocolpos due to transverse vaginal septum 6 years back and was operated twice for the same. First, the hematocolpos was aspirated, the tract was dilated and evacuation of hematocolpos was done. Fibrosis occurred after 2 months and amenorrhea persisted for 6 years. Second, incomplete resection of the fibrosed transverse vaginal septum was done and a mold was kept for 1 year. On examination, recurrent fibrosis of transverse vaginal septum leading to hematometra and hematocolpos was found. Complete resection of septum with double breasting of vaginal mucosa was done. Drain was kept in vagina for 7 days. Patient was advised to keep the mold for 1 and half year.
\end{abstract}

How to cite this article: Paryani D, Desai A, Shah K, Patel SN. A Case Report of Recurrent Fibrosis in Case of Transverse Vaginal Septum. J South Asian Feder Menopause Soc 2014;2(1):42-43.

\section{Source of support: Nil}

Conflict of interest: None

\section{INTRODUCTION}

Transverse vaginal septum forms during embryogenesis when mullerian ducts fuse improperly to the urogenital sinus. It is generally located at lower $2 / 3$ rd and upper $1 / 3$ rd junction of vagina. Site of location of transverse vaginal septum in descending order of occurrence is $46 \%$ in upper vagina, $40 \%$ in mid-vagina and $14 \%$ in lower vagina. ${ }^{3}$ Incidence of obstructive mullerian anomalies is 0.1 to $3.8 \%$. Occurrence of transverse vaginal septum is 1 in 70,000 females. ${ }^{1}$ Complete transverse vaginal septum can cause primary amenorrhea, hematometra, hematocolpos. Incomplete septa or a perforate septa presents with hypomenorrhea, dyspareunia and infertility. Differential diagnosis of transverse vaginal septum includes vaginal agenesis or aplasia. Endometriosis is found in these patients due to retrograde menstruation but is reversible with treatment. ${ }^{2}$ USG and MRI help in diagnosis of location of septum and

\footnotetext{
${ }^{1,3}$ Senior Resident, ${ }^{2}$ Professor, ${ }^{4}$ Gynecologist

${ }^{1-4}$ Department of Obstetrics and Gynecology, GMERS Medical College, Sola, Gujarat, India
}

Corresponding Author: Swati Nilay Patel, Gynecologist Department of Obstetrics and Gynecology, GMERS Medical College, Sola, Gujarat, India, e-mail: patelswati1972@gmail.com thickness of the septum. Surgical excision is required to get normal path of menstrual blood outflow but important point of caution in surgery is choice of method which has less recurrence by fibrosis as well establishing normal vaginal canal dimension to prevent dyspareunia. High vaginal septum and thick vaginal septum lead to inappropriate anastomosis of vaginal wall leading to higher chances of stricture leading to restenosis. ${ }^{3}$ Tense hematocolpos leads to stretching of septum and hence decrease in thickness of the septum. ${ }^{4}$ A Foley's catheter kept for 2 weeks after septum excision can prevent stricture formation. ${ }^{3}$ Vaginal pull through surgery for low and thin vaginal septum and push through (by abdominal route) can aide complete resection of septum preventing stricture. ${ }^{5}$ Use of mold properly up to 1 year depending on the patient can help prevent restenosis. ${ }^{5} \mathrm{Z}$ plasty is also an effective method of treating transverse vaginal septum. ${ }^{6}$ In case of a stricture, second look surgery with excision of fibrosis or $\mathrm{Z}$ plasty may be needed.

\section{CASE REPORT}

A 21-year-old female reported with secondary amenorrhea, lower abdominal pain and dyspareunia. Her active married life was 3 months. At age of 15 years she consulted a gynecologist for primary amenorrhea and lower abdominal pain. On examination, she was found to have normal female phenotype. Per rectal examination showed bulging cystic mass about $3 \mathrm{~cm}$ from introitus. Ultrasound revealed hematocolpos, normal uterus and normal ovaries. Examination under anesthesia revealed transverse vaginal septum at the junction of upper and middle 1/3rd of vagina. Aspiration and evacuation was done. Tract was dilated. She had regular menstruation for two cycles. Again amenorrhea developed and persisted for 5 years duration without any lower abdominal pain. At age of 20 years she started developing lower abdominal pain. Ultrasound showed hematometra (32.241 cc volume). Resection of transverse vaginal septum was done and vaginal mold was kept. After irregular bleeding for 1 month, amenorrhea persisted for 1 year. After 1 year she presented with lower abdominal pain, severe dyspareunia and secondary amenorrhea. No mass was palpable abdominally. Pelvic examination showed $4 \mathrm{~cm}$ vaginal length and fibrosis was visualized at upper end of vagina. Per rectal examination showed small bulge beyond vagina. Ultrasound showed 
hematometra and hematocolpos ( $53.2 \mathrm{ml}$ volume). Operative procedure of resection of fibrosis at site of transverse vaginal septum was planned under GA. Fibrosis was present at $4 \mathrm{~cm}$ depth of vagina. Transverse incision of $4 \mathrm{~mm}$ was made. Dilator of same size was introduced and direction of dilator kept upward and anteriorly. Gradual dilatation up to $10 \mathrm{~mm}$ done. About 30 to $40 \mathrm{cc}$ of brownish colored collected blood came. Suction was not done for drainage. Head end of patient was raised to allow drainage by gravity. Resection of septum by cutting fibrotic tissue along edge of $10 \mathrm{~mm}$ dilator was done by sharp small cuts of $2 \mathrm{~mm}$ at 12 , $3,6,9$ o'clock position over fibrotic tissue. Lower edge of vagina above transverse vaginal septum was caught with allis forceps at 12,3, 6, 9 o'clock positions and upper edge of vagina below septum was also caught in the same manner. Vaginal edges were sutured by double breasting technique using vicryl 2 to 0 . A drain made from $5 \mathrm{ml}$ syringe was used for drainage of collected blood. The nozzle was cut to make a wide opening and edges were blunted. One week later the mold was replaced by acrylic mold with $1 \mathrm{~cm}$ hole at the apex. Patient was advised to keep the mold for one and half year and perform regular intercourse. Six month follow-up showed no collection in uterus and vagina, normal menstrual periods and no dyspareunia.

\section{DISCUSSION}

Transverse vaginal septum is a rare congenital mullerian variety. It is usually asymptomatic during childhood and early adolescent period. After menarche, it usually presents with primary amenorrhea. Abdominal pain is not a presenting feature because of variable size of collection of blood in uterus and vagina. Surgery is always needed to allow normal menstrual blood flow, prevention of dyspareunia and fertilility gain. Improperly resected septum can evolve from a microperforate septum to a completely occluded septum due to stricture at the site of septum. ${ }^{7}$

Recurrent fibrosis poses a major problem requiring recurrent surgery disturbing quality of life of patients with transverse vaginal septum. Complete resection of transverse vaginal septum with double breasting technique of suturing of vaginal mucosa and proper use of vaginal mold can help prevent recurrent fibrosis.

\section{REFERENCES}

1. Gibson ED. Transverse upper vaginal septum presenting in pregnancy: a case report and review of the literature. Aust NZJ Obstet Gynaecol 2003;43:381.

2. Bradshaw K, Stuart L. Stanton, Philippe Zimmern. Female Pelvic Reconstructive surgery; page 54.

3. Gezginç K, Yazıcı F, Karataylı R. A new technique for the treatment of transverse vaginal septum by foley catheter. J Pediat Adolescent Gynecology. 2011 Oct;24(5).

4. Beyth Y, Klein Z, Weinstein S. Thick transverse vaginal septum: expectant management followed by surgery. J Pediatric and Adolescent Gynecology 2004 Dec;17(6).

5. van Bijsterveldt C, Willemsen W. Treatment of patients with a congenital transversal vaginal septum or a partial aplasia of the vagina. The vaginal pull-through versus the push-through technique. J Pediatric Adolescent Gynecology 2009 June;22(3).

6. Wierrani F, Bodner K, Spängler B, Grünberger W. Z-plasty of the transverse vaginal septum using Garcia's procedure and the Grünberger modification. Fertil Steril 2003 Mar;79(3):608-612.

7. Nichols JL. Secondary amenorrhea attributed to occlusion of microperforate transverse vaginal septum. Fertil Steril 2010 June;94(1):351. 